\title{
Conexões entre cultura e desenvolvimento: o terceiro setor na gestão cultural e encaminhamentos das Organizações da Sociedade Civil
}

\author{
Conexiones entre cultura y desarrollo: el tercer sector en la gestión \\ cultural y encaminamientos de las Organizaciones de la Sociedad Civil
}

\section{Connections between culture and development: the third sector in the culture and referrals management of Civil Society Organizations}

Icaro Vasques Inchauspe ${ }^{1}$

Bruno César Alves Marcelino ${ }^{2}$

\begin{abstract}
Resumo
O presente estudo procurou prover a discussão intersetorial sobre desenvolvimento na gestão pública com a entrada da chamada terceira via ou terceiro setor nos tempos hodiernos. Fomentado por novos atores através da participação de organizações da sociedade civil com a finalidade de compreender de que forma a criação deste setor dialoga com o Estado na formação e construção do chamado desenvolvimento, tendo como foco a área da cultura e na formação de políticas culturais, como um novo ponto de partida no compartilhamento das funções de gerenciamento da administração pública entre Estado, sociedade e mercado. Para realização do estudo, foram analisados quantitativamente dados orçamentários referentes ao estado de São Paulo pormenorizando os encaminhamentos das organizações da sociedade civil na gestão cultural local.
\end{abstract}

Palavras-Chave: cultura e desenvolvimento; terceiro setor; organizações da sociedade civil; participação social; gestão cultural.

\section{Resumen}

El presente estudio buscó promover la discusión intersectorial sobre el desarrollo en la gestión pública con la entrada de la llamada tercera vía o tercer sector en los tiempos modernos. Fomentado por nuevos actores a través de participación de organizaciones de la sociedad civil con la finalidad de comprender de qué forma la creación del sector dialoga con el Estado en la formación y construcción del llamado desarrollo, especificamente haciendo foco en el área de la cultura y en la formación de políticas culturales, como un nuevo punto de partida en el intercambio de las funciones de gerenciamiento de la administración pública entre Estado, sociedad y mercado. Para la realización del estudio, fueron analizados cuantitativamente datos sobre

\footnotetext{
${ }^{1}$ Mestrando em Antropologia; Universidade Federal de Pelotas; Pelotas, Rio Grande do Sul - Brasil; icarovasques@gmail.com.

${ }^{2}$ Bacharel em Produção e Política Cultural, Mestrando em Integração Contemporânea da América Latina; Centro Latino-Americano de Estudos em Cultura - CLAEC; Foz do Iguaçu, Paraná, Brasil; brunomarcelino@claec.org.
} 

e-ISSN 2016/Atual: 2525-7870 | e-ISSN 2015/2016: 2447-018X

presupuestos referentes al estado de San Pablo, pormenorizando los encaminamientos de las organizaciones de la sociedad civil en la gestión cultural local.

Palabras clave: cultura y desarrollo; tercer sector; organizaciones de la sociedad civil; participación social; gestión cultural.

\section{Abstract}

This study sought to promote intersectoral discussion on development in public management with the entry of socalled third way or third sector in modern times. Fomented by new actors through the participation of civil society organizations in order to understand how the creation of this dialogue sector with the State in the formation and construction of the so-called development, specifically applied in the field of culture and the formation of cultural policies, as a new starting point in the sharing of management functions of public administration between state, society and market. For realization of the study were analyzed quantitatively budget data for the state of São Paulo detailing referrals of civil society organizations in local cultural management.

Keywords: culture and development; third sector; civil society organizations; cultural management.

\section{Introdução}

Abordaremos inicialmente alguns ideais introdutórios conceituais que constituem componentes para programas e ações de desenvolvimento afirmado por Bresser-Pereira ${ }^{3}$, pensador teórico e defensor deste ideal, que mais tarde virá a ser o principal responsável pela reforma da gestão pública aplicado as novas formas e conceitos sobre a administração e gerencialismo público, que será tratado mais à frente. Também traremos a discussão sobre desenvolvimento baseado em obras de Celso Furtado ${ }^{4}$, mais especificamente a partir do livro Ensaios sobre cultura e o Ministério da Cultura organizado por Rosa Freire d' Aguiar que vão além da esfera teórica político-econômica e suas dimensões (micro e macroeconômicas) para compreensão de um desenvolvimentismo amplo, introduzido às novas dinâmicas sociais e à participação da sociedade-civil organizada no início dos 90, agora atuantes como novos agentes, empreendedores e prestadores de serviços nas áreas da saúde, educação, e não menos importante, e que será ressalvada especificamente neste trabalho, o setor da cultura.

Neste primeiro momento faremos uma passagem inicial acerca de alguns acontecimentos relacionados à concepção primaria de desenvolvimento no contexto brasileiro perpassando até o objeto de estudo proposto com as modificações na administração pública através da intersetorialidade 5 .

\section{Panorama histórico acerca do desenvolvimento na administração pública brasileira}

Entre os anos de 1930 a 1970, o Brasil e demais países latino-americanos cresceram em ritmos extraordinários. Muitos entenderam que a partir de uma queda brusca e enfraquecimento do centro capitalista para criação e formulação de novas estratégias

\footnotetext{
${ }^{3}$ Ministro da Administração e Reforma do Estado no governo de Fernando Henrique Cardoso (1995-1998).

${ }^{4}$ Ministro do Planejamento de João Goulart (1962) e Ministro da Cultura do governo Sarney (1988). Criador da primeira legislação de incentivo fiscal à cultura.

${ }^{5}$ Ação focada na busca da promoção de produtos sociais em comum. É a ação ou parceria em que todos os setores irão compartilhar tecnologias e desfrutar dos benefícios diretamente. Deve ser o eixo estruturador das políticas públicas, possibilitando uma abordagem geral dos problemas sociais. Ver Teixeira e Pereira (2013).
} 

e-ISSN 2016/Atual: 2525-7870 | e-ISSN 2015/2016: 2447-018X

nacionais que buscassem o desenvolvimento, tendo como base a promoção do Estado e a política de proteção as indústrias nacionais.

No Brasil especificamente, temos início claramente na era Vargas, na década de 30, onde faremos uma análise mais aprofundada, pois acreditamos que este período deu a origem há um insulamento burocrático de desenvolvimento, com uma mão dupla, de autoritarismo e centralização de poder, mas que a partir daí ramificou-se em demais modelos de desenvolvimentismo na administração pública com a criação do Departamento Administrativo do Serviço Público (DASP) ${ }^{6}$ na reforma administrativa, destinada a organizar e racionalizar o serviço público no país. Entre algumas de suas atribuições do DASP como aprimoramento foi o de assumir a responsabilidade pela elaboração da proposta do orçamento federal, chegando a exercer forte influência sobre as políticas governamentais então implementadas na época.

O modelo de administração pública criado, inaugura uma nova era por três relações: A primeira, o pensamento de uma construção no formato de expandir o papel de atuação do Estado, prevendo a intervenção nos domínios econômico e social em nome de um projeto nacional-desenvolvimentista Abrucio (apud Martins, 1976; Bresser-Pereira, 2008). O que se pretendia era a introdução do processo de construção nacional por intermédio de um novo tipo estatal voltado para a industrialização, a urbanização, e o desenvolvimento econômico do país.

Preparando de forma intensa para construção do projeto de state-building ${ }^{7}$, de forma a criar uma administração pública competente, capaz de implementar e conduzir diretrizes de modernização econômica e desenvolvimento, como descreve Abrucio na fala de Rezende (2004, p, 48):

\begin{abstract}
"O esforço de state-building pelo desenvolvimento nacional em ampla escala, iniciado com o governo Vargas em 1930 dependeria em muito da construção de uma burocracia com maior performance. Essa foi uma das principais razoes para o início de uma grande reforma administrativa.
\end{abstract}

Evidente que o entendimento além de Estado-nação é também a modernização da burocracia brasileira na estrutura weberiana destinada a produzir políticas públicas em larga escala (Abrucio, 2000) com a compreensão de um pacto de união dos entes federativos nacionais com vistas em um projeto nacional-desenvolvimentista.

Segundo Bresser-Pereira (2007) a premissa norteadora do pensamento nacionaldesenvolvimentista foi baseada em:

[...] primeiro lugar, que o objetivo básico dessa política era promover o desenvolvimento econômico, e em segundo lugar, que, para que isso acontecesse, a nação - ou seja, empresários, burocracia do Estado, classes médias e trabalhadores, unidos na competição internacional - precisava definir os meios para alcançar esse objetivo no âmbito do sistema capitalista, com o Estado como o principal instrumento da ação coletiva.

Tendo como um de seus principais pensadores na criação de um grupo de economistas desenvolvimentistas como cita Bresser-Pereira, criaram um ramo da economia - a teoria econômica do desenvolvimento - composta com a participação do ex-ministro Celso Furtado, no espectro do planejamento econômico e no campo da cultura como desenvolvimento, do qual abordaremos mais especificamente, feitas as devidas proposições.

6 Sobre o DASP ver a Formação da burocracia brasileira (2000) e a Era Vargas, link: http://cpdoc.fgv.br/producao/dossies/AEraVargas1/anos37-45/PoliticaAdministracao/DASP

${ }^{7}$ Processo de construção do Estado na busca pelo desenvolvimento nacional ver Bresser-Pereira (2000) 
Este pensamento da teoria econômica do desenvolvimento se filiava a três escolas de pensamento: escola clássica de Smith e Marx, teoria macroeconômica keynesiana e a teoria estruturalista latino-americana.

O Brasil e demais países da América-latina que passaram pela experiência colonial, continuaram ideologicamente dependentes do centro, após sua independência formal, com um certo atraso no pensamento desenvolvimentista. Bresser-Pereira (2007) aponta que desenvolvimentismo era nacionalista porque, para se tornarem industriais, esses países precisaram constituir seus estados nacionais. O nacionalismo presente no desenvolvimentismo era a ideologia para formar um estado nacional; era a afirmação de que, para se desenvolver, os países precisavam definir suas próprias políticas e instituições.

Dessa forma em 1955, no governo de Juscelino Kubitscheck, iniciou a implantação de uma política econômica liberal sobe forte influência estadunidense no país. Seu governo foi conhecido popularmente como nacional-desenvolvimentista, cuja meta associa-se ao programa de desenvolvimento econômico pelo crescimento da industrialização e da infraestrutura, típicos exemplares de setores desenvolvimentista de integração nacional como a própria construção de uma capital nacional, Brasília, fazendo assim, progredir cinquenta anos em cinco.

Com isso trouxe riscos inflacionários enormes para o país na medida que Jânio Quadros renúncia em 1961 e após o golpe do Estado no governo de João Goulart, no período da ditadura civil-militar (1964-1985) que tinha como reformas políticas voltadas para as áreas sociais, como a pretensão para as reformas de base, entre elas, agrária, política, educacional, cultural, esta já permeando com a criação das primeiras políticas culturais, e demais estruturas públicas. Neste mesmo período, tivemos governos ditatoriais com o pensamento de centralização do aparato de Estado-nação com grande preocupação de nação-ufanista com obras faraônicas ${ }^{8}$ aludindo a infraestruturas enormes e de pouca importância útil.

Apesar de ter feito aliança política com o Estados Unidos (no período autoritário e ditatorial, principalmente contra o comunismo), o Brasil, a partir das políticas acionadas, passou de agrário para industrial, de uma formação social mercantilista para uma formação capitalista, e de uma condição semicolonial para a de uma nação. Nesse sentido, desenvolvimentismo, foi o nome dado a estratégia nacional de desenvolvimento a partir de sua ideologia que prospectou tais modificações.

Este novo modelo político de desenvolvimento teve sua funcionalidade como característica principal nos anos de 1930 a 1980, a partir da entrada de novos processos de trocas em âmbito mundial, com a introdução da globalização no cenário dos atores estatais e novas formas de compartilhamento das políticas sociais como estratégias de naçãodesenvolvimentista, como desenvolvimento na área da cultura no qual surge a terceira via, ou o terceiro setor, com a entrada e fortalecimento das organizações da sociedade civil no compartilhamento do gerenciamento da administração pública em tempos de crise sistêmico do capital.

Em 1995, no governo FHC, com o ministro da Administração Federal e Reforma do Estado (MARE) por Bresser-Pereira, teve início no Brasil, a Reforma da Gestão Pública ${ }^{9}$ ou

\footnotetext{
${ }^{8}$ Devido a censura ao governo militar, o termo para críticas foi denominado de faraônicos - das grandes obras para os Faraós, deuses egípcios.

${ }^{9}$ Nos primeiros quatros anos do governo FHC (1994) a partir a reforma foi executada pelo Ministério da Administração Federal e Reforma do Estado - MARE. Sendo reformulado por decisão do próprio ministro Bresser-Pereira passou a gestão para o Ministério do Planejamento e Gestão (1998). Atualmente após algumas modificações das gestões atuais, é chamado de Ministério do Planejamento, Orçamento e Gestão (2016).
} 

e-ISSN 2016/Atual: 2525-7870 | e-ISSN 2015/2016: 2447-018X

reforma gerencial do Estado com a publicação, nesse ano, do Plano Diretor da Reforma do Estado enviada e aprovada ao Congresso Nacional virando a Emenda Constitucional da Administração Pública em 1998.

Tendo com objetivos constituídos neste plano em contribuir para um Estado forte e eficiente. Compreendendo três dimensões: a) dimensão institucional-legal, voltada a descentralização da estrutura organizacional do aparelho do Estado através da criação de novos formatos organizacionais, como agencias executivas, regulatórias e as organizações sociais; b) dimensão da gestão pela maior autonomia e a introdução de três novas formas de responsabilização dos gestores - a administração por resultados, a competição administrada pela excelência e o controle social - em substancia parcial dos regulamentos rígidos, da supervisão e auditoria que caracterizam a administração burocrática; c) uma dimensão cultural, de mudança de mentalidade, visando passar da desconfiança generalizada que caracteriza a administração burocrática para uma desconfiança maior, ainda que limitada, própria da administração gerencial.

A partir destas premissas pensados como novas formas de administração pública aplicada com marcos gerenciais e de controle social, surge aí então novos mecanismos de compartilhamento de gestão como forma de desenvolvimento na formulação de políticas públicas, sob uma nova compreensão de cultura da qual descreveremos as modificações conceituais básicas entre cultura e desenvolvimento.

\section{Relações entre cultura e desenvolvimento}

Esboçado um breve panorama sobre os acontecimentos e noções primárias no contexto histórico do desenvolvimentismo no Brasil e suas terminologias aplicadas numa ótica de permutação primária de política econômica clássica da teoria, apontada por Bresser-Pereira, abordaremos como a cultura no pensamento de Celso Furtado e demais autores fortalecem a ideia de como o termo cultura pode ser potencializado nas razões de Estado-nação como fator principal do desenvolvimento. Ainda assim, traremos algumas noções de políticas culturais de âmbito nacional para exemplificar o ponto central desta discussão.

Na visão de Borja (2009) a partir do processo de desenvolvimento das forças produtivas, a análise do subdesenvolvimento busca apreender as características da infraestrutura econômica de um determinado sistema nacional, para então interpretar a interação desta como a superestrutura política, cultural e ideológica. Trata-se, em última instância, de identificar as formas de produção e de apropriação do excedente e suas repercussões sobre a composição das classes hegemônicas no país. Estabelecida uma hegemonia, esta passaria a nortear os valores culturais e ideológicos, consolidados como expressão da identidade nacional e do interesse comum.

Portanto ocorre nesta cadeia, que o sistema surge como um dos componentes do sistema nacional e no, estudo do subdesenvolvimento pensado por Celso Furtado, precisa ser contextualizado dentro do sistema mundial. Entretanto, no seu interior, o sistema de cultura abarca relações que lhe são especificas, entre a cultura material e cultura não-imaterial seria composta pelos bens utilizados tanto para consumo quanto para produção, e a cultura nãomaterial estaria entrelaçado nas relações sociais de produção, organização política e social, nos costumes, religião, hábitos e etc.

"O que existe de fundamental e comum aos dois modelos é a constatação de que, sendo a cultura um conjunto de elementos interdependentes, toda vez que em determinadas condições históricas avança a tecnologia e se desenvolvem as bases 
materiais, todos os demais elementos serão chamados a justar-se às novas condições, ajustamentos estes que darão origem a uma série de novos processos, com repercussões inclusive sobre a base material." (Furtado, 1964, p. 19).

Incorporando ao cerne da discussão, indo ao pensamento de Celso Furtado enquanto um conjunto de interdependências operacionalizadas por um sistema, tal sistema está imbricado através de suas características e peculiaridades, que tentaremos esclarece-lo para chegar a uma noção de cultura para analise proposta, nos tempos hodiernos.

Respaldado neste pensamento de material e não-material no processo de cultura hegemônica, como muitos autores apontam, inserido num sistema de produção dos novos meios de desenvolvimento, - aqui teremos um sistema de produção cultural Coelho (1997) enviesada pelo capital, dá-se a cultura num sentido stricto pela luta de classes. Porém, Cuche (1999) vai dizer que a cultura não está circunscrita a círculos, camadas ou grupos sociais: “a cultura pode existir sem consciência de identidade, ao passo que as estratégias de identidade, podem manipular e até modificar uma cultura". ${ }^{10}$

Aplicando esta nova compreensão e noção de cultura, saindo do viés, restrito e limitado que é o viés sociológico, que em sua análise abarca uniformemente os acontecimentos de um tempo histórico restringindo-se somente a grupos, camadas ou círculos sociais, como mencionado acima, passando para um processo de pensamento antropológico de um conceito da cultura como um conjunto de saberes-fazeres humano. Na intepretação de Geertz (2008, p. 4) cultura é assumida não como uma ciência experimental em busca de leis, mas como uma ciência interpretativa, à procura de significado. Portanto, podemos defender, por este prisma antropológico, que uma cultura fornece os conhecimentos, valores, símbolos, que orientam e guiam as vidas humanas (MORIN, 2003, p.48). Segundo CHATI (2012, p.18) "um sistema de desenvolvimento pela cultura poderia então ter como um de seus objetivos a difusão e ampliação do acesso a própria cultura? Poderia ter como premissa diminuir lacunas entre fruídores e fazedores dessa cultura? " Para referenciarmos esta concepção, buscamos um conceito amplo no âmbito de uma política internacional que abarca largamente este conceito. No entendimento da UNESCO, cultura pode ser definida como:

Conjunto dos traços distintivos, espirituais e materiais intelectuais e afetivos que caracterizam uma sociedade ou um grupo social e que abrange, além das artes e das letras, os modos de vida, as maneiras de viver juntos, os sistemas de valores, as tradições e as crenças (DUDC 2001, p.1)

Ainda restrita esta definição orientada pela Unesco, já há um entendimento da cultura como a integração dos sistemas de valores e formas de viver juntos, e a inclusão dos saberesfazeres tradicionais ou não científicos, no rol dimensional da cultura. Os elementos que seriam representativos de uma cultura, tornam-se amplos na gama das expressões humanas que estariam neste conjunto. A noção de cultura traz uma contribuição relacionada ao processo dinâmico de trocas, interações e inter-relações.

Neste entendimento, este conceito se consolida no Relatório: Investir na diversidade e no dialogo intercultural (Riddi, Unesco, 2009) que traz modificações e na integração deste elemento: " a cultura é entendida mais como processo: as sociedades vão-se modificando de acordo com caminhos que lhes são próprios. " (Riddi, 2009, p. 4). Evidenciando-se a própria restrição da Unesco e das demais políticas culturais por serem aplicadas primeiramente ao entendimento de cultura no sentido material-físico, sobretudo agora, entendo a imaterialidade e sensibilidade das relações como um processo cultural.

\footnotetext{
10 Para estudo especifico sobre a abordagem de identidade cultural ver "A Identidade cultural na pós-
} modernidade" Stuart Hall (2004). 
Com isso, o que podemos compreender num primeiro momento, é a definição da cultura como um conjunto complexo da produção subjetiva e material humana (CHATI, 2010, p. 212). Logo esta compreensão, na visão de Celso Furtado e demais autores supracitados, entendem o desenvolvimento através da cultura, interligados num complexo sistema interdependente através dos saberes-fazeres não mais limitando-se a esfera material no tempoespaço, mas sim através das dinâmicas e das transformações culturais. Ainda assim, complementa Chati (2012) "se a cultura é entendida como processo, pode-se dizer que um sistema cultural deve então estabelecer uma estrutura organizativa para estimular a criação, circulação, troca e fruição dos bens e experiências culturais de determinado local e grupo social".

Com isso, esse ambiente deveria sustentar-se em mecanismos capazes de garantir que esses fluxos se mantenham em níveis que satisfaçam as necessidades culturais da população e promovam o desenvolvimento de suas representações simbólicas (COELHO, 1997). Um sistema que tem por função primaria estimular fluxos, e ainda tem como objetivo o desenvolvimento, torna a tarefa mais complexa.

Neste sentindo a partir de um pensamento amplo de integração nacional a partir da cultura pelo desenvolvimento, criando assim, no viés antropológico que compreende pela diversidade cultural numa visão descentralizada, entendendo a cultura como um processo e não como algo dado. Em 2003 no governo Lula numa visão burocrática weberiana instituiu o Sistema Nacional de Cultura (SNC) visando normatizar a administração pública da cultura com base num modelo que reúna a sociedade civil e os entes federativos da República União, estados e municípios com seus respectivos sistemas de cultura, organizados de forma autônoma e em regime de colaboração.

À semelhança de outros sistemas de políticas públicas, o SNC é uma articulação entre Estado e sociedade que pretende dar organicidade, racionalidade e estabilidade às políticas públicas de cultura - definidas como políticas de Estado. A finalidade principal é garantir a todos os brasileiros o efetivo exercício de seus direitos culturais. Após os inúmeros avanços ocorridos nos últimos anos no campo da cultura e da gestão cultural em nosso país, os maiores desafios que hoje se apresentam são, de um lado, assegurar a continuidade das políticas públicas de cultura como políticas de Estado, com um nível cada vez mais elevado de participação e controle social. E, de outro, viabilizar estruturas organizacionais e recursos financeiros e humanos, em todos os níveis de governo, compatíveis com a importância da cultura para o desenvolvimento do país (SNC, 2003, p. 14).

Ancorados pela visão tripartite na gestão de políticas públicas e referendada na Constituição de 1988, o Ministério da Cultura, a partir do ano de 2003 e da criação e institucionalização desta política cultural de Estado, entende que para o seu desenvolvimento, parte da concepção que compreende a cultura em três dimensões: a simbólica, a cidadã e a econômica. Essas três dimensões, que incorporam visões distintas e complementares sobre a atuação do Estado na área cultural, inspiram-se nos direitos culturais e buscam responder aos novos desafios da cultura no mundo contemporâneo.

Ao adotar essa dimensão, a política cultural supera também as fronteiras entre as políticas públicas, atravessando-as transversalmente. Nesse sentido é estratégica a relação da política cultural com as políticas de educação, comunicação social, meio ambiente e turismo, além das políticas de ciência e tecnologia, esporte e lazer, saúde e segurança pública, entre outras.

Daremos ênfase principalmente à dimensão simbólica, cuja faz parte dos argumentos que no plano internacional defendem a necessidade de se considerar os fatores culturais nos 
planos e projetos de desenvolvimento. Essas posições enfatizam que o crescimento econômico, "divorciado de seu contexto humano e cultural, não é mais que um crescimento sem alma. "Foram esses argumentos que levaram o PNUD"1 a formular o conceito de desenvolvimento humano, que avalia o desempenho dos países por uma gama de critérios que vão "da liberdade política, econômica ${ }^{12}$ e social às oportunidades individuais de saúde, educação, produção, criatividade, dignidade pessoal e respeito aos direitos humanos".

Portanto, cabe ao Estado compreender e englobar a noção de cultura nos projetos de desenvolvimento de integração nacional e na modernização do aparato estatal e modernização dos meios de gestão - gradativamente e ainda assim questionável - já é possível, verificar alguns avanços e procedimentos deste modelo tripartite em alguns estados brasileiros, através da participação da sociedade civil no modelo de gestão compartilhada que caracteriza a criação do SNC, tendo como seus princípios: diversidade das expressões culturas; universalização do acesso aos bens e serviços culturais; fomento à produção, difusão e circulação de conhecimento e bens culturais; cooperação entre os entes federados, os agentes públicos e privados atuantes na área cultural; integração e interação na execução das políticas, programas, projetos e ações desenvolvidas; complementaridade nos papéis dos agentes culturais; transversalidade das políticas culturais; autonomia dos entes federados e das instituições da sociedade civil; transparência e compartilhamento das informações; democratização dos processos decisórios com participação e controle social e descentralização articulada e pactuada da gestão, dos recursos e das ações.

Tratando-se de uma política cultural de Estado, com aspectos modernizadores na gestão compartilhada na tomada de decisões (CANCLINI, 2001, p. 65) costumam assumi-la como "intervenções do Estado, instituições civis e grupos organizados da comunidade para orientar o desenvolvimento de formas simbólicas, as necessidades culturais da população e obter consenso para um tipo de ordem ou transformação social". Portanto, a continuidade de aplicar a análise de um contexto nacional brasileiro, para chegarmos a uma noção atualizada de política cultural que integre a pluralidade das mais diversas manifestações artísticasculturais do país. Na obra de Furtado, na construção destas políticas ainda se tem uma leitura instrumentalizada, invariavelmente associada à aspectos sociopolíticos e socioeconômicos, que enfatiza resultados objetivos que a cultura poderia promover.

Assim, é possível verificar uma configuração de política cultural como resposta às demandas sociais (COELHO, 1997) e uma política cultural como estratégia consorciada do Estado e da Sociedade Civil (COELHO, 2008). Nortearemos a discussão a partir da reforma do Estado que coloca a Sociedade Civil no cerne da gestão pública no campo das políticas setoriais, criando novos mecanismos de dialogo nas chamadas gestões compartilhadas promovendo novos conhecimentos organizacionais através da participação social.

\section{Gestão intersetorial e terceiro setor na cultura}

Compreendendo as reformas administrativas no âmbito do Estado como norteadoras de um desenvolvimento como integração nacional, dá-se então, passo aos novos marcos regulatórios e de gerenciamento da administração pública. Através das reformas do Estado e sua concepção de administração e gerencialismo público, já abordado aqui, a partir do Plano

\footnotetext{
${ }^{11}$ Programa das Nações Unidas para o Desenvolvimento

12 Temos aqui uma noção de desenvolvimento além das esferas sociopolíticas e socioeconômicas. Ver Furtado (1978)
} 
RELACult - Revista Latino-Americana de Estudos em Cultura e Sociedade

Revista Latinoamericana de Estudios en Cultura y Sociedad | Latin American Journal of Studies in Culture and Society

V. 03, ed. especial, ago., 2017, p. 166-185 | relacult.claec.org e-ISSN 2016/Atual: 2525-7870 | e-ISSN 2015/2016: 2447-018X

Diretor de Reforma do Aparelho do Estado (PDRAE) alocada no Setor de serviços nãoexclusivos:

[...] Que corresponde ao setor onde o Estado atua simultaneamente com outras organizações públicas-não estatais e privadas. As instituições desse setor não possuem o poder de Estado. Plano Diretor da Reforma do Aparelho do Estado 42 Este, entretanto, está presente porque os serviços envolvem direitos humanos fundamentais, como os da educação e da saúde, ou porque possuem "economias externas" relevantes, na medida que produzem ganhos que não podem ser apropriados por esses serviços através do mercado. As economias produzidas imediatamente se espalham para o resto da sociedade, não podendo ser transformadas em lucros. São exemplos deste setor: as universidades, os hospitais, os centros de pesquisa e os museus. (PDRAE, 1995 p. 41).

Objetivando:

“a) Transferir para o setor público não-estatal estes serviços, através de um programa de "publicização", transformando as atuais fundações públicas em organizações sociais, ou seja, em entidades de direito privado, sem fins lucrativos, que tenham autorização específica do poder legislativo para celebrar Plano Diretor da Reforma do Aparelho do Estado contrato de gestão com o poder executivo e assim ter direito a dotação orçamentária; b) Lograr, assim, uma maior autonomia e uma consequente maior responsabilidade para os dirigentes desses serviços; c) Lograr adicionalmente um controle social direto desses serviços por parte da sociedade através dos seus conselhos de administração. Mais amplamente, fortalecer práticas de adoção de mecanismos que privilegiem a participação da sociedade tanto na formulação quanto na avaliação do desempenho da organização social, viabilizando o controle social; d) Lograr, finalmente, uma maior parceria entre o Estado, que continuará a financiar a instituição, a própria organização social, e a sociedade a que serve e que deverá também participar minoritariamente de seu financiamento via compra de serviços e doações; e). Aumentar, assim, a eficiência e a qualidade dos serviços, atendendo melhor o cidadão-cliente a um custo menor.". (PDRAE, 1995, p. 47).

\begin{tabular}{|c|c|c|c|c|c|}
\hline & Estatal & $\begin{array}{l}\text { Pública } \\
\text { Não Estatal }\end{array}$ & Privada & Burocrática & Gerencial \\
\hline $\begin{array}{l}\text { NÚCLEO ESTRATÉGICO } \\
\text { Legislativo, Judiciário, } \\
\text { Presidência, Cúpula dos } \\
\text { Ministérios, Ministério } \\
\text { Público }\end{array}$ & & & & & \\
\hline $\begin{array}{l}\text { ATIVIDADES EXCLUSIVAS } \\
\text { Regulamentaçăo } \\
\text { Fiscalizaçăo, Fomento, } \\
\text { Segurança Pública, } \\
\text { Seguridade Social Básica }\end{array}$ & & & & & \\
\hline $\begin{array}{l}\text { SERVIÇOS NÃO- } \\
\text { EXCLUISVOS } \\
\text { Universidades, Hospitais, } \\
\text { Centros de Pesquisa, } \\
\text { Museus }\end{array}$ & Publicizaçấo & & & & \\
\hline $\begin{array}{l}\text { PRODUÇÃO PARA O } \\
\text { MERCADO } \\
\text { Empresas Estatais }\end{array}$ & & Privatizaçăo & & & \\
\hline
\end{tabular}


Tabela 1: Composição dos setores do Estado e formas de Propriedade do PDRAE. Fonte: PDRAE

Partindo da aplicação para a objetivação deste Plano setorial do Estado definido como Serviço não-exclusivo, foi preciso a criação de políticas públicas na tomada de decisão ampla, principalmente no entorno das políticas sociais, torna necessário integrar diversos atores sociais e organizacionais na gestão destas políticas, privilegiando a ação intersetorial.

Segundo Junqueira (2004) a intersetorialidade integra saberes e experiências das políticas setoriais, e constitui um fator de inovação na gestão da política e possibilita articulação das diversas organizações que atuam no âmbito das políticas sociais, constituindo as redes sociais. Portanto, a intersetorialidade e a rede, para dar eficiência e eficácia a gestão das políticas sociais exigem mudanças significativas na lógica tanto das organizações públicas estatais como das organizações sem fins lucrativos, integrando-as para atender os interesses coletivos. Nesse sentido, Cunha (2011) define a gestão cultural:

\begin{abstract}
Podemos considerar que a gestão cultural é uma profissão contemporânea complexa que, além de estabelecer um compromisso com a realidade de seu contexto sociocultural, político e econômico, tem ainda o desafio de estruturar um processo formativo para estes profissionais, seja no ambiente não formal, seja na academia. A gestão cultural já é reconhecida por seu papel na mediação e as instancias políticas e a sociedade, tanto no meio empresarial quanto no meio artístico e no relacionamento com o público. E essas ações são cada vez mais especializadas. (CUNHA, 2011, p. $35)$.
\end{abstract}

As organizações públicas, responsáveis por essa gestão, por motivos diversos, não têm conseguido realizar essa tarefa. O impasse vivido pelo setor público faz com que se busque novas saídas e dentre elas as organizações do terceiro setor constitui uma das alternativas privilegiadas para fazer frente aos problemas sociais que afetam o conjunto da população. São espaços institucionais que não se restringem apenas a um setor, são organizações que materializam a realidade intersetorial. São espaços que desenvolvem a cidadania (Oliveira e Junqueira, 2003).

Portanto, o conceito de gestão intersetorial e de rede cria novas possibilidades de intervenção, gerando em cada um de seus membros a participação que viabiliza a reconstrução da sociedade civil. Ocasiona a criação de respostas novas aos problemas sociais, tornando mais eficaz a gestão social, que se caracteriza por ser intersetorial, articulando instituições e pessoas para construírem projetos, recuperar a vida e a utopia. Neste sentido, com avanços setoriais de gestão, através de marcos regulatórios dá-se início com o Marco Regulatório das Organizações da Sociedade Civil (MROSC) aprovado em 2014 com modificações até o seu vigor no ano de 2016, por meio da Secretária Geral do Governo Federal visando modernizar as relações do poder público com as Organizações da Sociedade Civil (OSCs). Afim de contemplar as demandas de controle social na atuação enquanto agentes não-estatais, mas com finalidade pública na atuação das parcerias celebradas entre as organizações e a Administração Pública Federal, dos estados e municípios.

A relevância desta nova inclusão pode ser evidenciada em dados divulgados pela pesquisa Fundações Privadas e Associações sem Fins Lucrativos (Fasfil) ${ }^{13}$ indicam que existem no Brasil 290,7 mil Organizações da Sociedade Civil. A maior parte delas surgiu após

\footnotetext{
${ }^{13}$ Instituto Brasileiro de Geografia e Estatística (IBGE); Instituto de Pesquisa Econômica Aplicada (Ipea); Grupo de Institutos, Fundações e Empresas (Gife) e Associação Brasileira de Organizações Não Governamentais (Abong). As Fundações Privadas e Associações sem Fins Lucrativos no Brasil.
} 
a promulgação da Constituição Federal de 1988, que reconheceu a organização e a participação social como direitos e valores a serem garantidos e fomentados.

Em relação ao mercado de trabalho ${ }^{14}$, as OSCs empregam, juntas, 2,1 milhões de trabalhadores formais assalariados, em uma média de 7,3 pessoas assalariadas por entidade. Esse contingente é bastante expressivo, já que equivale a 4,9\% dos trabalhadores formais brasileiros, ou quase $1 / 4(23,0 \%)$ do total dos empregados na administração pública no mesmo ano.

Neste sentido, a administração pública vem atuando num formato de compartilhamento da gestão de políticas sociais e principalmente o governo do estado de São Paulo, onde através da criação da figura institucional da Organização Social (OS) criada no Brasil em 1998, por meio da Lei Federal n 9.637, com o intuito de viabilizar a execução de atividades não exclusivas do Estado por organizações da sociedade civil. Essa lei estabelece que o Executivo pode qualificar como organização social, pessoa jurídica de direito privado, sem fins lucrativos, cujas atividades sejam dirigidas ao ensino, à pesquisa científica, ao desenvolvimento tecnológico, à proteção e preservação do meio ambiente, à cultura e à saúde, à proteção e conservação do meio ambiente e à promoção de investimentos, de competitividade e de desenvolvimento.

As Organizações Sociais no estado de São Paulo na área da cultura são instituições não-governamentais, associações ou fundações de direito privado e sem fins lucrativos que atuam na área cultural, qualificadas a partir de critérios definidos em lei para atuar em parceria com o governo do Estado, por meio da Secretaria da Cultura (SEC SP) através dos contratos de gestão ${ }^{15}$ para execução de seus programas culturais, equipamentos e grupos artísticos. A Secretaria da Cultura do Governo do Estado vem adotando esse modelo de gestão em parceria com organizações sociais de cultura desde 2004.

A nível comparativo, a partir da existência dos contratos de gestão, mostraremos a presença das Organizações Sociais na gestão cultural do estado paulista. Os dados orçamentários foram retirados do Boletim Um, número 2 "10 anos de parceria com OSs de Cultura" 16 onde traz dados relacionados aos dez anos de adoção desse modelo de gestão pela SEC SP. As informações apresentadas foram obtidas em fontes e documentos oficiais, sempre referenciados. Os gráficos apresentados trazem valores em unidades de medidas que variam, e arredondamento no caso das cifras em milhares e milhões, a fim de facilitar sua visualização e leitura. Os segmentos culturais encontrados no novo modelo de gestão cultural dos espaços públicos estão classificados em: a) Formação Cultural; b) Difusão Cultural; c) Museus; e d) Bibliotecas.

\footnotetext{
${ }^{14}$ Dados retirados da Cartilha do Marco Regulatório das Organizações da Sociedade Civil (2014).

${ }^{15}$ Instrumento jurídico que institui e disciplina a parceria entre o Poder Público e uma entidade qualificada como Organização Social, para a execução de atividades de interesse social e utilidade pública. Esse instrumento estabelece atribuições, responsabilidades e obrigações de parte a parte, com o montante de recursos disponíveis para execução do plano de trabalho, as metas de desempenho e as formas de avaliação. Desde 2004, a Secretaria da Cultura do Estado de São Paulo vem adotando esse modelo para a gestão de seus programas culturais, equipamentos e grupos artísticos em parceria com Organizações Sociais de Cultura.

${ }^{16}$ O Boletim UM é uma publicação da Secretaria da Cultura do Estado de São Paulo produzida por sua Unidade de Monitoramento, para divulgar informações de interesse público sobre atividades exercidas pela Secretaria, inclusive relativas à sua política, organização, serviços e parcerias.
} 
RELACult - Revista Latino-Americana de Estudos em Cultura e Sociedade

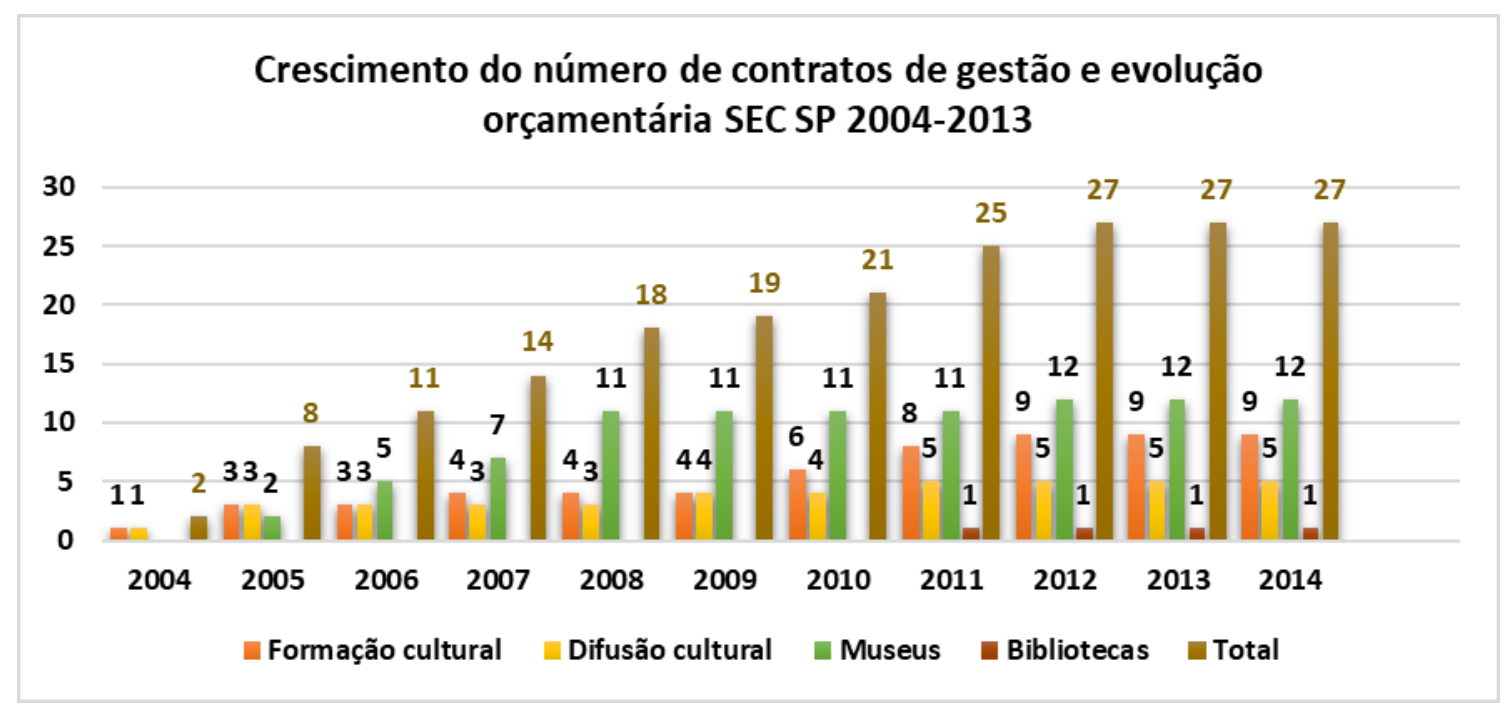

Gráfico 1: Crescimento do número de contratos de gestão e a evolução orçamentária da SEC SP entre 2004-2014. Fonte: SEC SP. Elaborado pelos autores.

A partir da adoção do modelo de gestão em parceria com organizações sociais, a Secretaria da Cultura ampliou progressivamente a contratualização de resultados com essas entidades do Terceiro Setor. Em dezembro de 2014 eram 27 contratos de gestão, com 20 organizações sociais de cultura. No gráfico abaixo veremos como se deu a evolução das despesas primárias e dos recursos aplicados nos contratos de gestão em números reais.

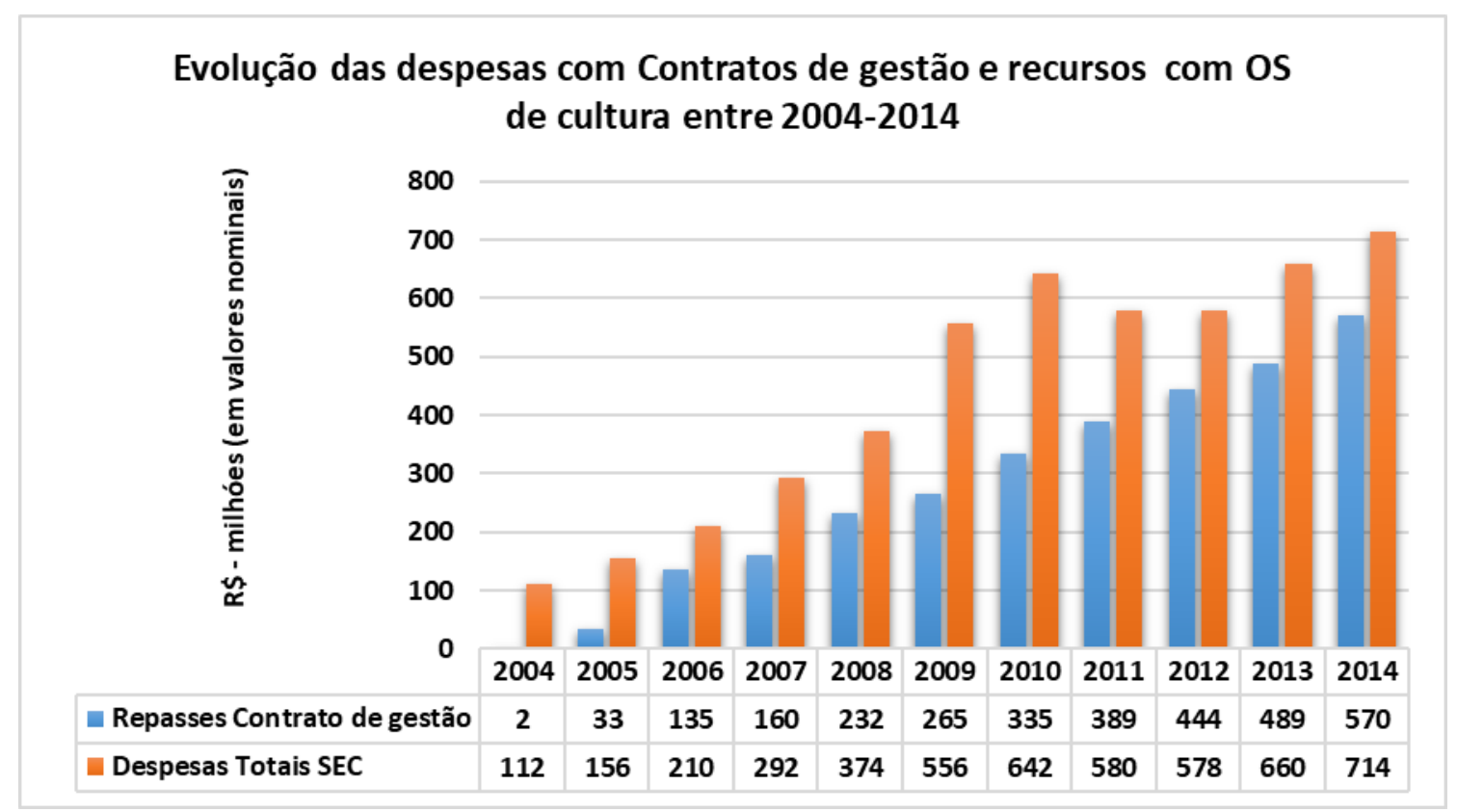

Gráfico 2: Evolução das despesas primárias da SEC SP e dos recursos aplicados em contrato de gestão com OS de cultura entre 2004-2014. Fonte: SEC SP. Elaborado pelos autores. 

e-ISSN 2016/Atual: 2525-7870 | e-ISSN 2015/2016: 2447-018X

Evidenciamos a evolução da execução orçamentária da Pasta da Cultura paulista, comparativamente à evolução dos recursos aplicados nas parcerias com organizações sociais de Cultura. É possível observar que o orçamento cresceu expressivamente, em parte graças à maior priorização dada pelo Governo Paulista à área cultural, num contexto econômico também favorável, e em parte devido à execução orçamentária praticamente integral realizada a cada ano, com resultados comprovados. A parceria com as OS tem sido fundamental para garantir essa execução e a comprovação das realizações.

Postos dados dos números orçamentários primários dos contratos de gestão, um importante indicador encontrado, são dos trabalhadores empregados no terceiro setor via contratação pela Consolidação das Leis Trabalhista (CLT):

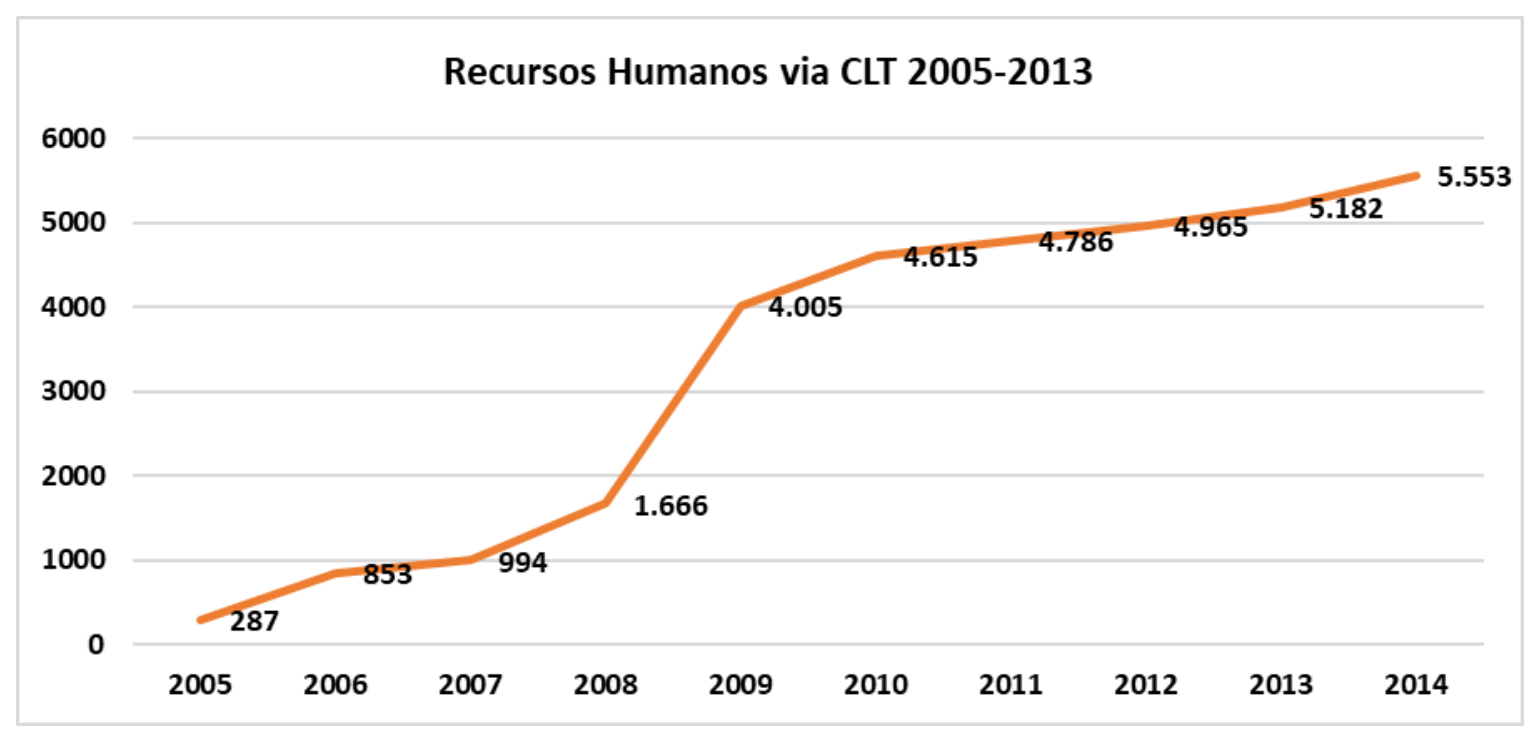

Gráfico 3: Recursos Humano via CLT da gestão 2005 a 2014. Fonte: SEC SP. Elaborado pelos autores.

Segundo os dados encontrados, a área cultural é uma das que mais depende de recursos humanos para viabilizar seus resultados. São músicos, atores, produtores, curadores, museólogos, cenógrafos, bailarinos, arte-educadores, bibliotecários, oficineiros, e muitos outros profissionais das áreas artísticas e culturais, além de gestores e pessoal administrativo. Em consequência disso, o custo de recursos humanos corresponde à principal despesa nos contratos de gestão, representando quase $60 \%$ dos repasses efetuados pelo Estado.

Além da inclusão de diversos profissionais na área da cultura, os modelos de gestão das OSs possuem autonomia afim de definir estratégias de desenvolvimento econômico de suas ações como algumas atividades para gerar receitas, (por meio de lojas, cafés, estacionamentos, publicações e outras), para ampliar o apoio da sociedade aos objetos contratuais (museus, teatros, oficinas e outros). Tanto as receitas financeiras, quanto a captação, receitas geradas a partir da venda de produtos e serviços, além de patrocínios captados com ou sem uso de leis de incentivo, são revertidos às realizações previstas no contrato de gestão. Abaixo, no gráfico 4 é possível verificar um crescente aumento em suas receitas: 


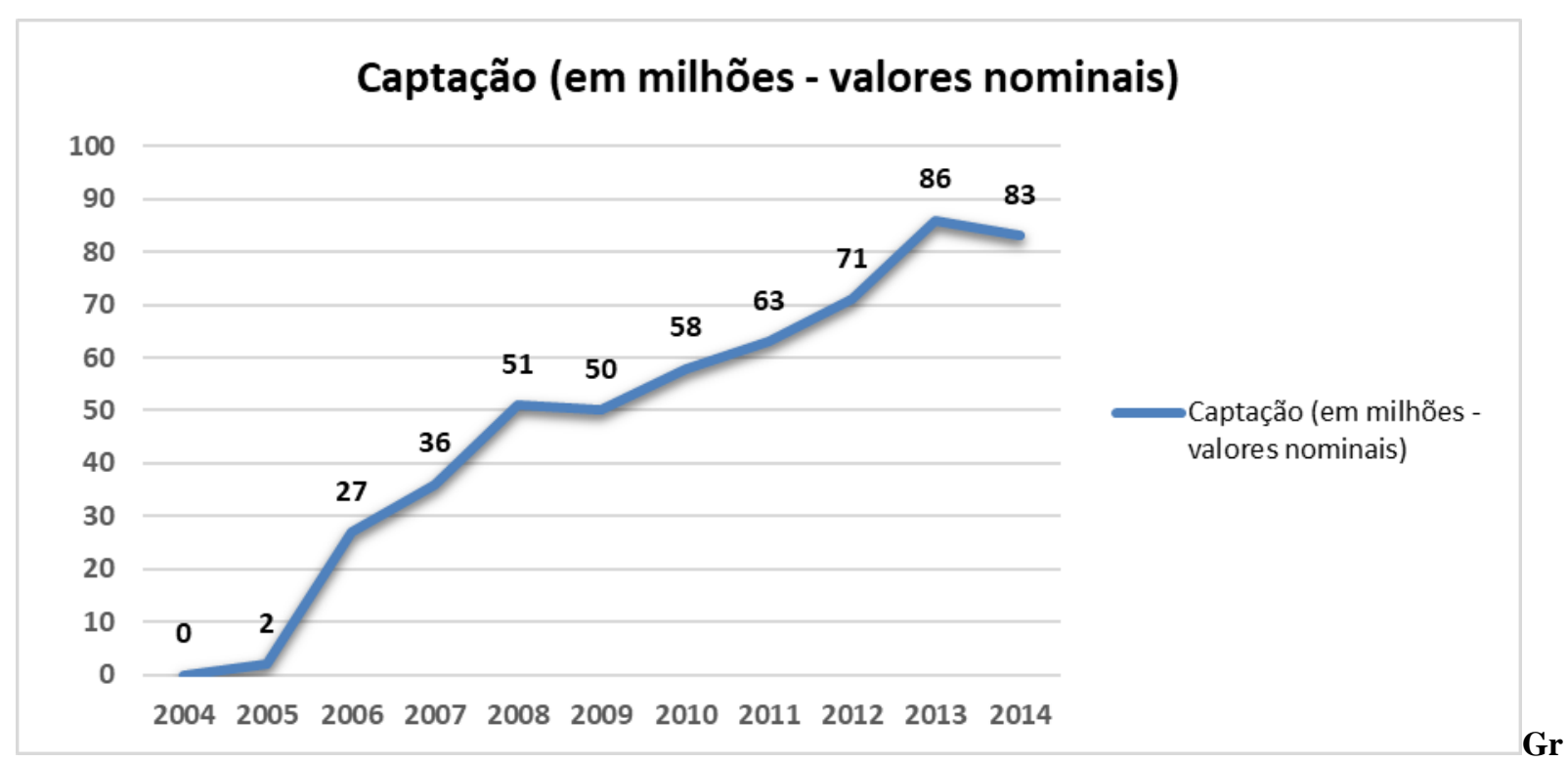

áfico 4: Evolução anual da captação de recursos feitas pelas OSs, somando toda as áreas. Fonte: SEC SP. Elaborado pelos autores.

Neste último gráfico, apontaremos em linhas gerais a porcentagem dos repasses anuais da SEC SP via convênios com as OSs, os segmentos culturais desenvolvidos trazendo a presença do público no desenvolvimento de suas atividades artísticas-culturais traçando um compilado geral da relevância que as OSs se tornaram na gestão cultural compartilhada com o estado de São Paulo para a produção artística-cultural enquanto desenvolvimento.

Repasses às Organizações Sociais

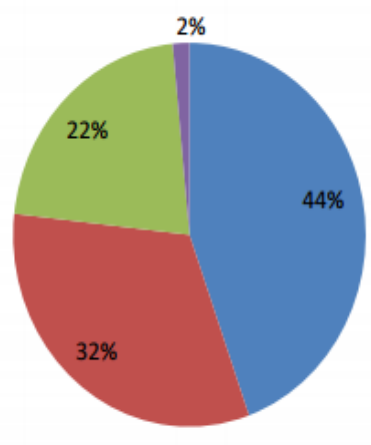

Atividades culturais

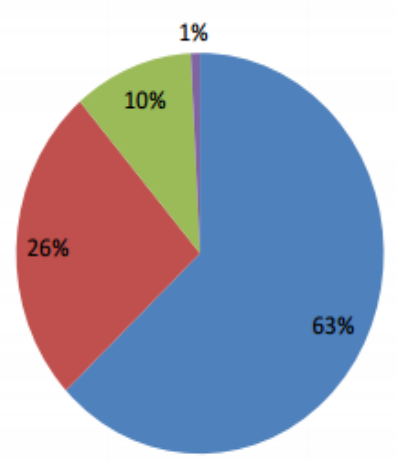

Público

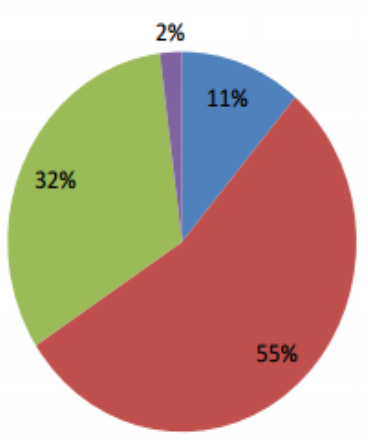

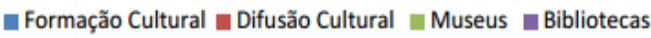

Gráfico 5: Compilado geral dos repasses orçamentários e atividades culturais propostas nos contratos de gestão via SEC SP. Fonte SEC SP. Elaborado pelos autores.

Percebe-se em relação ao primeiro gráfico por meio de Repasses às Organizações Sociais via contratos de gestão da SEC SP as OS em média de 44\% para formação cultural, entendendo-as como oficinas, aulas, workshops, trocas de experiências, $32 \%$ para difusão 
cultural para atividades, exposições, mostras artísticas-culturais, shows musicais, teatros, entre outros meios de difundir o produto cultural, 22\% dos repasses indo ao encontro da gestão de espaços museológicos, e apenas $2 \%$ para as bibliotecas. Evidencia-se no gráfico de Atividades Culturais as atividades somam-se a maioria em formação cultural com $66 \%$ e as demais atividades respectivas em $26 \%$ de difusão cultural, $10 \%$ para museus e caindo de 2 para $1 \%$ no setor das bibliotecas.

Porém, temos um revés no último gráfico referente ao Público, totalizando $56 \%$ em difusão de cultural, devido ao tamanho e proporção aportado em shows, festivais, espetáculos, mostras e exposições, $32 \%$ referente ao público alvo ao espaço museológico, e somente $11 \%$ de público para formação cultural, e $2 \%$ no espaço das bibliotecas.

Ainda assim, a cabo de transparência proposto pela SEC SP com as Organizações Sociais do terceiro setor, mapeamos as OS com contratos de gestão vigentes até o presente ano, do qual podem ser verificadas na tabela abaixo, tipificando de suas ações publicizadas nos gráficos acima através do segmento cultural da qual exercem as atividades qualificadas em formação cultural, difusão cultural, museus e bibliotecas:

\begin{tabular}{|c|c|c|c|c|}
\hline \multicolumn{5}{|c|}{ Organizações Sociais com contratos de gestão vigentes (2016) } \\
\hline OS & Cidade & Segmento & Atividades desenvolvidas & $\begin{array}{l}1^{\circ} \text { contrato de } \\
\text { gestão }\end{array}$ \\
\hline $\begin{array}{l}\text { A Casa - } \\
\text { Artes e Areu de } \\
\text { Brasileiros }\end{array}$ & São Paulo/SP & Museus & $\begin{array}{l}\text { Exposições, atividades } \\
\text { culturais }\end{array}$ & $02 / 05 / 2008$ \\
\hline Abaçaí Cultura e Arte & São Paulo/SP & $\begin{array}{c}\text { Formação } \\
\text { Cultural }\end{array}$ & Artesanato/cultura popular & $18 / 04 / 2005$ \\
\hline $\begin{array}{l}\text { Associação Amigos do } \\
\text { Projeto Guri - AAPG }\end{array}$ & São Paulo/SP & $\begin{array}{c}\text { Formação } \\
\text { Cultural }\end{array}$ & $\begin{array}{l}\text { Cursos de música, canto } \\
\text { coral, cordas, percussão }\end{array}$ & $26 / 11 / 2004$ \\
\hline $\begin{array}{l}\text { Associação Cultural de } \\
\text { Apoio ao Museu Casa } \\
\text { de Portinari - ACAM } \\
\text { Portinari }\end{array}$ & Brodowski/SP & Museus & $\begin{array}{l}\text { Difusão do patrimônio e } \\
\text { memória }\end{array}$ & $14 / 07 / 2008$ \\
\hline $\begin{array}{l}\text { Associação } r \text { de } \\
\text { Cultura, Educação e } \\
\text { Assistência Social } \\
\text { Santa Marcelina }\end{array}$ & São Paulo/P & $\begin{array}{c}\text { Formação } \\
\text { Cultural }\end{array}$ & Escola de música & $27 / 12 / 2007$ \\
\hline $\begin{array}{l}\text { Associação dos Amigos } \\
\text { do Conservatório de } \\
\text { Tatuí - AACT }\end{array}$ & Tatuí/SP & $\begin{array}{l}\text { Formação } \\
\text { Cultural }\end{array}$ & Escola de música & $22 / 12 / 2005$ \\
\hline $\begin{array}{lr}\text { Associação } & \text { dos } \\
\text { Amigos do Paço das } \\
\text { Artes } & \text { Francisco } \\
\text { Matarazzo Sobrinho }\end{array}$ & São Paulo/SP & $\begin{array}{l}\text { Difusão } \\
\text { Cultural }\end{array}$ & $\begin{array}{l}\text { Exposições de arte } \\
\text { contemporânea/conferencias, } \\
\text { workshops, atividades de } \\
\text { forma geral. }\end{array}$ & $30 / 11 / 2006$ \\
\hline
\end{tabular}


RELACult - Revista Latino-Americana de Estudos em Cultura e Sociedade

Revista Latinoamericana de Estudios en Cultura y Sociedad | Latin American Journal of Studies in Culture and Society

V. 03, ed. especial, ago., 2017, p. 166-185 | relacult.claec.org e-ISSN 2016/Atual: 2525-7870 | e-ISSN 2015/2016: 2447-018X

\begin{tabular}{|c|c|c|c|c|}
\hline $\begin{array}{l}\text { Associação dos } \\
\text { Artistas Amigos da } \\
\text { Praça - ADAAP }\end{array}$ & São Paulo/SP & $\begin{array}{l}\text { Difusão } \\
\text { Cultural }\end{array}$ & \begin{tabular}{|lr} 
Produção de & bens culturais: \\
espetáculos & teatrais, \\
exposições, & publicações, \\
audiovisual. &
\end{tabular} & $01 / 09 / 2010$ \\
\hline $\begin{array}{l}\text { Associação Museu } \\
\text { Afro Brasil - AMAB }\end{array}$ & São Paulo/SP & Museu & $\begin{array}{l}\text { Exposições temporárias, } \\
\text { Universo cultural africano e } \\
\text { afro-brasileiro }\end{array}$ & $22 / 06 / 2009$ \\
\hline $\begin{array}{l}\text { Associação Museu de } \\
\text { Arte Sacra de São } \\
\text { Paulo - SAMAS }\end{array}$ & São Paulo/SP & Museu & $\begin{array}{l}\text { Documentação de objetos } \\
\text { religiosos, exposição do } \\
\text { acervo, estudos e pesquisas } \\
\text { sobre a arte sacra e história } \\
\text { da arte. }\end{array}$ & $01 / 07 / 2007$ \\
\hline \begin{tabular}{|l|} 
Associação Paulista dos \\
Amigos da Arte - \\
APAA
\end{tabular} & São Paulo/SP & $\begin{array}{l}\text { Difusão } \\
\text { Cultural }\end{array}$ & $\begin{array}{l}\text { Produção de festivais e } \\
\text { programas continuados de } \\
\text { música, literatura, dança, } \\
\text { teatro e circo. }\end{array}$ & $18 / 11 / 2004$ \\
\hline $\begin{array}{l}\text { Associação Pinacoteca } \\
\text { Arte e Cultura - APAC }\end{array}$ & São Paulo/SP & Museu & $\begin{array}{l}\text { Exposições de obras de arte, } \\
\text { e gestão do Memorial da } \\
\text { Resistência }\end{array}$ & $01 / 01 / 2016$ \\
\hline Associação Pró-Dança & São Paulo/SP & $\begin{array}{l}\text { Difusão } \\
\text { Cultural }\end{array}$ & $\begin{array}{l}\text { Montagens de excelência } \\
\text { artística, que incluem } \\
\text { trabalhos dos séculos XIX, } \\
\text { XX e XXI de grandes peças } \\
\text { clássicas e modernas a obras } \\
\text { contemporâneas. }\end{array}$ & $01 / 12 / 2009$ \\
\hline \begin{tabular}{|l|} 
Catavento Cultural e \\
Educacional
\end{tabular} & São Paulo/SP & $\begin{array}{l}\text { Difusão } \\
\text { Cultural }\end{array}$ & $\begin{array}{l}\text { Espaço museológico e } \\
\text { difusão da ciência na área da } \\
\text { educação }\end{array}$ & $25 / 07 / 2007$ \\
\hline $\begin{array}{|lr|}\text { Fundação } & \text { Orquestra } \\
\text { Sinfônica do } & \text { Estado } \\
\text { de São Paulo } & \\
\end{array}$ & São Paulo/SP & $\begin{array}{c}\text { Formação } \\
\text { Cultural }\end{array}$ & $\begin{array}{l}\text { Realização, capacitação e } \\
\text { promoção de atividades } \\
\text { musicais. Escola de música }\end{array}$ & $01 / 11 / 2005$ \\
\hline \begin{tabular}{|l|} 
IDBRASIL Cultura, \\
Educação e Esporte
\end{tabular} & São Paulo/SP & Museus & $\begin{array}{l}\text { Gestão de espaço } \\
\text { museológico, Museu do } \\
\text { Futebol (2008) e Museu da } \\
\text { Língua Portuguesa (2012). }\end{array}$ & $08 / 09 / 2008$ \\
\hline \begin{tabular}{|l|} 
Instituto de \\
Preservação e Difusão \\
da História do Café e \\
da Imigração - INCI
\end{tabular} & Santos/SP & $\begin{array}{l}\text { Difusão } \\
\text { Cultural }\end{array}$ & $\begin{array}{l}\text { Gestão de espaço } \\
\text { museológico, Museu do } \\
\text { Café e Museu da Imigração }\end{array}$ & $18 / 12 / 2008$ \\
\hline Instituto Pensarte & São Paulo/SP & $\begin{array}{l}\text { Difusão } \\
\text { Cultural }\end{array}$ & $\begin{array}{l}\text { Gestão integral das } \\
\text { atividades de fomento com a } \\
\text { Orquestra de Jazz Sinfônica. }\end{array}$ & $16 / 12 / 2011$ \\
\hline $\begin{array}{|lrr|}\text { Poiesis - Instituto de } \\
\text { Apoio à Cultura, a } \\
\text { Língua e a Literatura }\end{array}$ & São Paulo/SP & $\begin{array}{l}\text { Difusão } \\
\text { Cultural }\end{array}$ & $\begin{array}{l}\text { Programas, } \text { Pesquisas, } \\
\text { oficinas voltadas para o } \\
\text { complemento da formação } \\
\text { dos estudantes. }\end{array}$ & $01 / 07 / 2008$ \\
\hline
\end{tabular}


RELACult - Revista Latino-Americana de Estudos em Cultura e Sociedade e-ISSN 2016/Atual: 2525-7870 | e-ISSN 2015/2016: 2447-018X

\begin{tabular}{|l|l|l|l|c|}
\hline $\begin{array}{l}\text { SP Leituras - São Paulo/SP } \\
\text { Associação Paulista de } \\
\text { Bibliotecas e Leitura }\end{array}$ & Bibliotecas & Incentivo à leitura & $01 / 04 / 2011$ \\
\hline
\end{tabular}

Tabela 2: Mapeamento das OS atuantes por atividades culturais no Estado de São Paulo, SEC SP. Elaborado pelos autores.

\section{Considerações finais}

As mudanças que vêm ocorrendo no interior do aparato estatal brasileiro têm na descentralização uma das suas principais diretrizes, significando transferências para as instâncias menores do poder e para entes públicos privados a gestão das políticas sociais com o objetivo de garantir à população seus direitos sociais. Esse processo vem assumindo características singulares em cada política, a partir, principalmente, da década de 1980, quando valoriza-se as organizações sem fins lucrativos como alternativa para agilizar a gestão das políticas sociais. Principalmente com o entendimento e através da reforma da gestão pública elaborada pelo ministro na época, Bresser-Pereira, descentralizando e compartilhando as ações estatais com as organizações sociais.

Neste novo modelo de gestão consolidado, é acentuado a partir de 2010, com a entrada dos marcos regulatórios das organizações da sociedade civil que fortalecem maior autonomia e compreensão das organizações sociais como prestadores de serviço atuantes junto ao Estado, principalmente no setor da cultura como abortado na presente pesquisa. Trazendo neste contexto, vimos que o Estado de São Paulo por meio da Secretária Estadual de Cultura através da celebração dos contratos de gestão subsidia em $40 \%$ as Organizações Sociais, através de seu orçamento total da pasta. Também é visível o poder de captação e crescimento de recursos das entidades tendo maior autonomia e descentralização em desenvolver suas atividades com êxito.

Cabe mencionar a diversidade do segmentos artísticos-culturais que as Organizações Sociais desenvolvem por meio de aplicação de lei estadual que vão desde a formação cultural, através da diversidade cultural, por meio de atividades de difusão cultural, como concertos musicais, peças teatrais, espetáculos circenses, festivais da mais diversas manifestações artística-culturais. Cabe ainda ressaltar os espaços museológicos auxiliando no espaço educacional, e a pouca participação das bibliotecas na gestão cultural. Diversidade que só pode ser alocada através da contratação de recursos humanos para operacionalização de profissionais qualificados em trabalhar com uma área tão subjetiva que é a cultura. Um grande número de profissionais contratados faz parte de uma gestão cultural descentralizada e compartilhada composta por novos atores na construção de políticas culturais voltadas para o terceiro setor.

Por tanto, a reforma da gestão pública buscou a descentralização, transferindo suas competências para outras instâncias governamentais na gestão das políticas sociais, criando novas possibilidades de gestão e parcerias. Nesse contexto, as Organizações da Sociedade Civil passaram a integrar esse movimento e articular-se em rede com outros organismos estatais e privados, privilegiando a ação intersetorial que ocasiona a criação de novas respostas aos problemas sociais.

A participação destes novos atores na gestão cultural local, exige mudanças significativas nas práticas das organizações, pois a possibilidade de participar não torna homogêneo os interesses que permeiam as relações sociais, inclusive pela descrença no poder de influenciar os acontecimentos. A cultura entendida como um processo das relações 

e-ISSN 2016/Atual: 2525-7870 | e-ISSN 2015/2016: 2447-018X

interpessoais como um dos fatores de desenvolvimento, entendida na sua diversidade e participação social através da modernização estatal partindo da burocracia para o modelo de gerencialismo através do compartilhamento de gestão do espaço público.

\section{Referências}

ABRUCIO, Fernando Luiz. Os laços federativos brasileiros: avanços, obstáculos e dilemas no processo de coordenação intergovernamental. 2000. Tese de Doutorado. Disponível em: http://pos.fflch.usp.br/node/44756. Acessado em 24/07/2016.

BORJA, Bruno. Cultura e desenvolvimento no pensamento de Celso Furtado. Bahia: UFBA, 2009. Disponível em: http://www.cult.ufba.br/enecult2009/19127.pdf. Acessado em 24/07/2016.

BRESSER-PEREIRA, Luiz Carlos. O modelo estrutural de gerência pública. Revista de Administração Pública 42.2 (2008): 391-410. Disponível em: http://www.scielo.br/scielo.php?script=sci_arttext\&pid=S0034-76122008000200009.

Acessado em 24/07/2016.

. Burocracia pública e classes dirigentes no Brasil. Revista

de Sociologia e Política, v. 28, p. 9-30, 2007. Disponível em: http://www.scielo.br/pdf/rsocp/n28/a03n28.pdf. Acessado em 24/07/2016.

\begin{tabular}{lcccr}
\hline PRDAE. & Brasília, & 1995. & Disponível & em: \\
http//www bresserpereira org br/documents/mare/planodiretor/planodiretor pdf & Acessado
\end{tabular}

\begin{tabular}{lcccr}
\hline PRDAE. & Brasília, & 1995. & Disponível & em: \\
http//www bresserpereira org br/documents/mare/planodiretor/planodiretor pdf & Acessado
\end{tabular}

- Plano Diretor da Reforma do Aparelho do Estado, em: $24 / 07 / 2016$.

CANCLINI, Néstor García. Definiciones en transición. CLACSO, 2001. Disponível em: biblioteca.clacso.edu.ar/ar/libros/grupos/mato/GarciaCanclini.rtf. Acessado em 24/07/2016.

COELHO, Teixeira. Dicionário Crítico de política cultural: Cultura e Imaginário. São Paulo: Iluminuras, 1997.

Iluminuras, 2008.

A cultura e seu contrário: cultura, arte e política pós-2001. São Paulo:

CUNHA, Maria Helena. Formação do profissional de cultura: desafios e perspectivas. Políticas Culturais em Revista, v. 4, n. 1, 2011. Disponível em: http://www.portalseer.ufba.br/index.php/pculturais/article/viewArticle/5314. Acessado em 24/07/16.

CHATI, Gabriel Medeiros. O processo de implementação do sistema municipal de desenvolvimento pela cultura de Joinville/SC. Dissertação de Mestrado.

CUCHE, Denys. A noção de cultura nas ciências sociais. Bauru: EDUSC, 1999. Disponível em:

http://www.usp.br/cje/anexos/pierre/CUCHeDAnocaodeculturanasCienciasSociaisCopia.pdf.

Acesso em 24/07/2016.

DA CUNHA REZENDE, Flávio. Por que falham as reformas administrativas?. FGV editora, 2004.

DE OLIVEIRA, Walter F.; JUNQUEIRA, Luciano A. Prates. Questões estratégicas na reforma sanitária: o desenvolvimento do terceiro setor. Revista de administração pública, v. 
RELACult - Revista Latino-Americana de Estudos em Cultura e Sociedade

Revista Latinoamericana de Estudios en Cultura y Sociedad | Latin American Journal of Studies in Culture and Society V. 03, ed. especial, ago., 2017, p. 166-185 | relacult.claec.org e-ISSN 2016/Atual: 2525-7870 | e-ISSN 2015/2016: 2447-018X

37, n. 2, p. 227-242, 2003. Disponível em: http://bibliotecadigital.fgv.br/ojs/index.php/rap/article/view/6485. Acessado em 24/07/2016.

FURTADO, Celso. Ensaios sobre cultura e o Ministério da Cultura. Rio de Janeiro: Contraponto, 2012.

GEERTZ, Clifford. A interpretação das culturas. $1^{\mathrm{a}}$ ed., $13^{\mathrm{a}}$ impressão. Rio de Janeiro. LTC, 2008.

https://identidadesculturas.files.wordpress.com/2011/05/geertz_clifford_a_interpretac3a7c3a3o_das_culturas.pdf. Acessado em 24/07/2016.

GOVERNO DO ESTADO DE SÃO PAULO. LEI COMPLEMENTAR $N^{\circ} 846$, de 4 de junho de 1998 que dispõe sobre qualificação de entidades como organizações sociais, e dá outras providencias.

Disponível

em: http://www.al.sp.gov.br/repositorio/legislacao/lei.complementar/1998/lei.complementar-84604.06.1998.html. Acessado em 24/07/2016

LEI COMPLEMENTAR $N^{o} 1.243$, de 30 de maio de 2014 que altera a Lei Complementar $n^{\circ}$ 846, de 1998, que dispõe sobre a qualificação de entidades como organizações sociais, e dá outras providencias. Disponível em: http://www.al.sp.gov.br/repositorio/legislacao/lei.complementar/2014/lei.complementar1243-30.05.2014.html. Acessado em 24/07/2016.

JUNQUEIRA, Luciano A. Prates. A gestão intersetorial das políticas sociais e o terceiro setor. Saúde e Sociedade, v. 13, n. 1, p. 25-36, 2004. Disponível em: www.revistas.usp.br/sausoc/article/download/7105/8577. Acessado em 24/07/2016.

LOUREIRO, Maria Rita Garcia; ABRUCIO, Fernando Luiz; PACHECO, Regina Silvia. Burocracia e política no Brasil: desafios para a ordem democrática no século XXI. FGV Editora, 2010.

MINISTÉRIO DA CULTURA. Estruturação, Institucionalização e Implementação do Sistema Nacional de Cultura. 2010. MinC/SESP-SP, 2010. Disponível em: http://www.cultura.gov.br/documents/10907/963783/livro11-602-paraaprovacao.pdf/d17c52f9-3a60-4196-af5c-a6655f028f3b. Acessado em 24/07/2016.

MORIN, Edgar. A cabeça bem-feita: repensar a reforma, reformar o pensamento. $8^{\text {a }}$ ed. Rio de Janeiro: Bertrand Brasil, 2003. Disponível em: http://www.uesb.br/labtece/artigos/A\%20Cabe\%C3\%A7a\%20Bem-feita.pdf. Acesso em 24/07/2016.

PRESIDÊNCIA DA REPÚBLICA. LEI N $N^{\circ}$ 9.637, de 15 de maio de 1998 que dispõe sobre a qualificação de entidades como organizações sociais e dá outras providencias. Disponível em: http://www.planalto.gov.br/ccivil_03/leis/L9637.htm. Acessado em 24/07/2016.

SECRETÁRIA DA CULTURA DO ESTADO DE SÃO PAULO. TRANSPARÊNCIA CULTURA. Disponível em: http://www.transparenciacultura.sp.gov.br/busca-contratos-degestao/. Visualizado em 24/07/16.

SECRETÀRIA GERAL DA PRESIDÊNCIA DA REPÚBLICA. Cartilha do Marco Regulatório das Organizações da Sociedade Civil. Brasília, 2014. Disponível em: http://www.secretariadegoverno.gov.br/iniciativas/mrosc/publicacoes/cartilha-mrosc.

Acessado em 24/07/2016. 

e-ISSN 2016/Atual: 2525-7870 | e-ISSN 2015/2016: 2447-018X

TRIBUNAL DE CONTAS DO ESTADO DE SÃO PAULO. Primeiro e Terceiro setores. Contratos de Gestão e Parcerias. Disponível em: http://www4.tce.sp.gov.br/sites/tcesp/files/downloads/cp_conv_tp_2014.pdf. Acessado em 24/07/2016.

UNESCO. DUDC. Declaração Universal sobre a Diversidade Cultural. Unesco, 2001. Disponível em: http://unesdoc.unesco.org/images/0012/001271/127160por.pdf. Acessado em 24/07/2016.

. Riddi. Investir na Diversidade e no dialogo intercultural. Unesco, 2009.

Disponível em: http://unesdoc.unesco.org/images/0018/001847/184755por.pdf. Acessado em 24/07/2016.

YANNE, KARINE; PEREIRA, LIMA; TEIXEIRA, SOLANGE MARIA. Redes $e$ intersetorialidade nas políticas sociais: reflexões sobre sua concepção na política de assistência social. Textos \& Contextos (Porto Alegre), v. 12, n. 1, p. 114-127, 2013. Disponível em: http://revistaseletronicas.pucrs.br/ojs/index.php/fass/article/viewFile/12990/9619. Acessado em 24/07/16. 